\title{
Revamping Occupational Safety and Health Training: Integrating Andragogical Principles for the Adult Learner
}

Alex Albert and Matthew R Hallowel, (University of Colorado at Boulder, USA)

\begin{abstract}
Despite attempts to improve safety performance, the construction industry continues to account for disproportionate injury rates. A large proportion of these injuries occur because workers are unable to recognize and respond to hazards in dynamic and unpredictable environments. Unrecognized hazards expose workers to unanticipated risks and can lead to catastrophic accidents. In order to enhance hazard recognition skills, employers often put new and experienced workers through formal hazard recognition training programs. Unfortunately, current training programs primarily rely on instructor-centric pedagogical approaches, which are insensitive to the adult learning process. In order to ensure effective adult learning, training programs must integrate learner-centric andragogical principles to improve engagement and retention in adult trainees. This paper aims to discuss training program elements that can potentially accelerate the adult learning process while improving safety knowledge retention. To this end, the researchers reviewed relevant literature on the cognitive processes of adult learning, essential components of effectual training programs and developed a reliable framework for the training and transfer of safety knowledge. A case example of successfully using the framework is also presented. The results of the study will provide safety trainers and construction professionals with valuable information on developing effective hazard recognition and receptor training programs, with the goal of improving construction safety performance.
\end{abstract}

Keywords: Hazard recognition training, Adult education, Construction Safety, Human resources development, Training framework

\section{Introduction}

Despite decades of research to improve safety performance in the construction sector, the industry continues to be a leading contributor to on-the-job injuries (Ahmed et al. 2000; Findley et al. 2004). Current trends in injury rates continue to reinforce that construction workers are more likely to be injured than workers in other industries (Cameron et al. 2008; Pinto et al. 2011; Roudsari and Ghodsi 2005) . In Australia, according to Safe Work Australia (2009), workers in the construction sector accounted for almost $25 \%$ higher injury rates when compared to the cumulative all-industry performance. Such high injury rates are typical of the global construction industry and occur partly because workers lack the required skill-sets to recognize and respond to hazards in a timely manner.

Construction safety management processes rely on the fundamental assumption that hazards can be reliably identified and controlled in dynamic construction projects. Unfortunately, results of recent studies conducted by Carter and Smith (2006) and the Center for Disease Control and Prevention (CDC 2012); reveal that construction personnel lack adequate skills to recognize hazards. Unrecognized hazards in the preconstruction safety evaluation process can result in a suboptimal safety plan and unanticipated hazardous conditions. 
Traditional approaches to safety management are reactive (Mitropoulos et al. 2005). Generally, a post-injury analysis is conducted to identify accident causal factors and deficiencies with current safety management programs, which then provide an opportunity to implement additional safety controls. With increased legislative requirements, dire financial implications (Waehrer 2007), potential for prosecution and even possible imprisonment for safety breaches (HSE 2012; Safe Work Australia 2009) employers are now seeking to incorporate proactive elements that can be introduced upstream to prevent injury occurrence (Hinze et al. 2013). One major avenue that is being extensively explored is providing workers with highly effective training programs to improve hazard recognition competency.

Although regulatory bodies mandate that employers provide sufficient training, current training methods fail to incorporate essential theories of learning that can significantly improve the effectiveness of imparting safety knowledge and skills-sets (Wilkins 2011). Most training programs are developed based on the naïve assumption that safety knowledge can easily be transferred through conventional classroom instructional methods. According to Haslam et al. (2005), these conventional training programs largely fail to engage trainees and may even instill negative attitudes towards safety issues. The problem is further aggravated by the use of incompetent trainers, ineffectual skill acquisition and delivery methods, and unorganized material that impede acquisition, retention, and transfer of safety knowledge. These traditional pedagogical methods, while being efficient to train young learners, are not suitable for selfdirecting adult learners (Wilkins 2011).

This paper explores the cognitive process through which adults learn and provides a reliable framework for designing highly effective hazard recognition training programs through the incorporation of andragogical principles. A preliminary case example of using the framework for training purposes is presented. It is expected that the results of the study can assist construction safety professionals to formulate hazard recognition training programs that can efficiently improve worker hazard recognition skills as a result of which better safety performance can be anticipated.

\section{Literature Review}

\section{Hazard recognition in Construction}

As shown in Figure 1, construction safety management involves recognizing hazards, assessment of safety risk, and devising safety strategies to prevent workers from being injured due to hazard exposure. As such, comprehensive hazard recognition is a pre-requisite to improving safety performance. Unfortunately, current formal hazard recognition methods have severe limitations and, as a result, a large proportion of hazards go unidentified. In a recent study, Carter and Smith (2006) examined hazard recognition levels in three U.K.-based construction projects. The proportion of unidentified hazards in the three projects ranged approximately between $10 \%$ and $36 \%$. In another study reviewing 100 individual construction accidents, Haslam et al (2005) postulated that $42 \%$ of accident occurred due to limitations of worker capability including the lack in safety knowledge and skill-sets. Similarly in a very recent study (Bahn 2012), new workers on average were unable to identified $57 \%$ of hazards in specific scenarios. These unrecognized hazards can led to catastrophic accidents, claiming several lives. Thus, there is an imminent need to develop high-potential training programs that can significantly improve worker competency in hazard recognition.

Albert, A and Hallowel, M R (2013) 'Revamping occupational safety and health training: Integrating andragogical principles for the adult learner', Australasian Journal of Construction Economics and Building, 13 (3) 128-140 


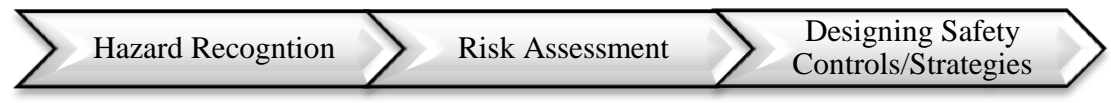

Figure 1 Conceptual illustration of construction safety management process

\section{Construction Safety Training}

As indicated, construction workers lack adequate hazard recognition skills. This lack in safety knowledge results from the failure of typical training programs (Haslam et al. 2005). Although legislative regulations require employers to provide adequate training to workers, some evidence indicate that employers do not make adequate investments in developing effective training programs (Holte and Kjestveit 2012). Most organizations continue to use the conventional classroom instructional method in order to fulfill regulatory requirements, rather than investing in more innovative and engaging methods of training. Effective training of workers is particularly a challenge in the construction industry due to the different types of work-tasks undertaken, interaction between diverse trades, and the fragmented nature of the industry.

Although employers value safety endeavors, the transient nature of the work-force has significantly impeded the use of more effective training methods (Holte and Kjestveit 2012). Investing in educating short-service workers for a single project is sometimes considered as being cost-prohibitive. According to Wang et al. (2010) employers are reluctant to train workers for several reasons such as: (1) trained workers may be attracted by competitors; (2) additional cost of training may increase cost of construction, due to which contractors may lose bids; (3) benefits of providing training such as improved productivity or safety is not quantified and communicated; (4) lack of commitment and interest of workers to accept formal training programs; (5) lack of evidence in implementing unproven training methods; (6) time constraint and productivity issues in typical projects; and (7) unavailability of required resources and dedication from project team. Despite barriers to implementing high-quality training programs, hazard recognition training is an essential component to improve safety performance and profitability. With the increase in the cost of injuries over the past 20 years and the recent focus on delivering zero-incident projects, owners have begun to pre-qualify contractors based on their past safety performance (Huang and Hinze 2006). Thus, it is a necessity in today's competitive market for employers to incorporate innovate, time-efficient and cost-effective training delivery methods to improve worker hazard recognition skills.

To ensure effective learning, training programs need to be tailored in accordance to the learning styles of the workers. Traditional pedagogical training programs in which the trainee plays a dependent or passive role is often ineffective for training adult learners (Wilkins 2011). Adult learners (workers) learn differently and hence andragogical principles need to be incorporated for effective knowledge transfer.

\section{Andragogy - the Theory of Adult Learning}

Traditional pedagogy is a teacher-directed authoritative educational system, where the teacher takes complete responsibility to design the material that will be learned, the instructional method that will be used, and the amount of time that will be allotted for each topic. On the other hand, the learner generally plays a more depended role and adjusts to the learning processes and requirements set by the teacher (Knowles et al. 2011). While pedagogical methods are very effective in imparting education to dependent young learners, they are less effective in

Albert, A and Hallowel, M R (2013) 'Revamping occupational safety and health training: Integrating andragogical principles for the adult learner', Australasian Journal of Construction Economics and Building, 13 (3) 128-140 
educating context-driven mature adults who prefer self-directing learning methods. In these circumstances, it is essential to incorporate andragogical principles where the learning methods are adopted based on the learner's interests and needs (Wilkins 2011). Training programs must not just focus on imparting knowledge or skill-sets, but must ensure that workers understand the benefits that will follow. When adult learners see value in the learning process, which can be established through the use of andragogical principles, there is more commitment to learning. Figure 2 illustrates the difference between the two theories of learning.

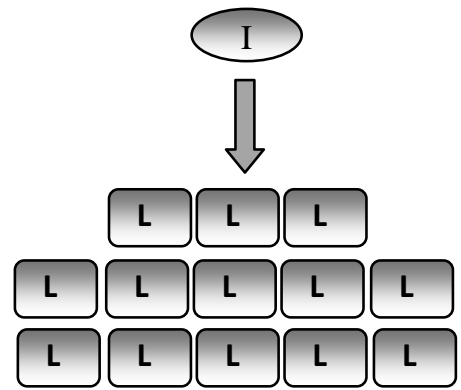

(a)Pedagogy based learning

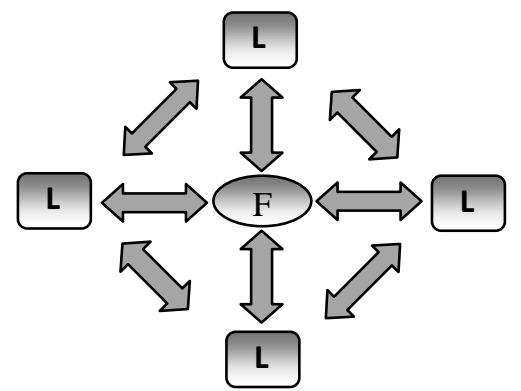

(b)Andragogy based learning

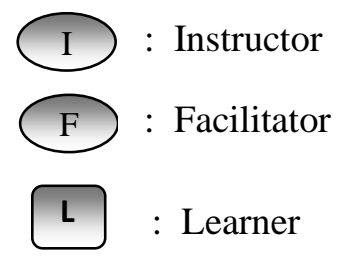

L : Learner

Figure 2 Schematic representation of two major theories of learning

Several studies have improved our current understanding of the adult cognitive learning process and, as a result, sophisticated andragogy-based adult accelerated learning techniques have been developed. Accordingly, there is a strong indication that adults learn differently when compared to younger learners (Rogers 1995). Linderman (1956) argues that adults are primarily motivated to learn when collaborative learning approaches are used to seek solutions to real-life problems that are commonly encountered. Therefore, educational and training programs designed for adults should facilitate mutual inquiry using mutual and inductive learning processes (see Figure 2), rather than providing authoritative instructions. As a result, the instructor when using andragogy based learning techniques plays the role of a facilitator of learning rather than a transmitter or evaluator of the learning process (Taylor and Kroth 2009). The facilitator relies on the learner's internal drive to learn while creating a risk-free learning environment that encourages exchanging of ideas and knowledge. Knowles et al. (2011) suggests that the learning environment must be characterized by physical comfort, mutual trust and respect, mutual helpfulness, freedom of expression, and acceptance of difference. In such an environment, the facilitator and the learners collaboratively develop learning objectives and material that are relevant to the goals and aspirations of individual learners. The andragogy based assumptions that differentiate self-directing adult learners from traditional dependent learners are summarized in Table 1 (Forrest and Peterson 2006; Knowles et al. 2011; Misch 2002).

Based on the differences between adult and traditional learners, Knowles et al. (2011) argues that training and educational programs must be designed to be learner-centric rather than being teacher-centric for adult learners. Elwood et al. (2008) provides a process model that can be used by andragogical facilitators to adopt adult learning processes into their educational and training programs. These process design elements along with brief descriptions are summarized in Table 2. Using these elements to reinforce learning in hazard recognition training programs may effectively improve construction safety performance.

Albert, A and Hallowel, M R (2013) 'Revamping occupational safety and health training: Integrating andragogical principles for the adult learner', Australasian Journal of Construction Economics and Building, 13 (3) 128-140 


\begin{tabular}{|c|c|c|}
\hline Assumptions & $\begin{array}{l}\text { Theory of adult learning } \\
\text { (Andragogy) }\end{array}$ & $\begin{array}{l}\text { Theory of traditional learning } \\
\text { (Pedagogy) }\end{array}$ \\
\hline Need to know (A1) & $\begin{array}{l}\text { Adult learners feel a need to know } \\
\text { precisely how learning will be } \\
\text { beneficial prior to undertaking the } \\
\text { learning process. }\end{array}$ & $\begin{array}{l}\text { Traditional learners generally need } \\
\text { not know precisely as to how } \\
\text { learning will be beneficial. The } \\
\text { follow directions that is provided by } \\
\text { the instructor to obtain favorable } \\
\text { feedback and evaluation }\end{array}$ \\
\hline $\begin{array}{l}\text { Self-concept of learners } \\
\text { (A2) }\end{array}$ & $\begin{array}{l}\text { Adult learners become } \\
\text { psychologically self-directing as } \\
\text { they mature and develop a self- } \\
\text { concept that they are capable of } \\
\text { making responsible decisions on } \\
\text { their own. They dislike being } \\
\text { directed or imposed by others / } \\
\text { external factors. }\end{array}$ & $\begin{array}{l}\text { Traditional learners are generally } \\
\text { dependent learners. They rely on } \\
\text { the expertise of the instructor and } \\
\text { accept most imposed learning } \\
\text { methods. }\end{array}$ \\
\hline $\begin{array}{l}\text { Experience of learners } \\
\text { (A3) }\end{array}$ & $\begin{array}{l}\text { Adult learners generally have } \\
\text { diverse backgrounds, experiences, } \\
\text { and varied learning styles. The } \\
\text { experiences that have been } \\
\text { acquired by adult learners over the } \\
\text { years are valuable resources for } \\
\text { the mutual learning and inquiry } \\
\text { process }\end{array}$ & $\begin{array}{l}\text { In traditional learning methods, the } \\
\text { experience of the teacher and other } \\
\text { instructional resources are the } \\
\text { primary source for imparting } \\
\text { knowledge. Traditional learners are } \\
\text { assumed to have minimal or no } \\
\text { experience in the areas under } \\
\text { consideration. }\end{array}$ \\
\hline Readiness to learn (A4) & $\begin{array}{l}\text { Adult learners are more open to } \\
\text { learn things that are essential to } \\
\text { solve practical problems they } \\
\text { encounter in real-life situations }\end{array}$ & $\begin{array}{l}\text { Traditional learners are ready to } \\
\text { learn anything that is imparted by } \\
\text { the instructor. }\end{array}$ \\
\hline $\begin{array}{l}\text { Orientation to learning } \\
\text { (A5) }\end{array}$ & $\begin{array}{l}\text { Adult learners are generally task or } \\
\text { problem-centered in that they seek } \\
\text { to learn practical lessons that they } \\
\text { perceive can assist them with } \\
\text { dealing with practical tasks and } \\
\text { problems they will encounter. }\end{array}$ & $\begin{array}{l}\text { Traditional learners are more } \\
\text { subject-oriented in that they follow } \\
\text { material content that is designed } \\
\text { based on some logic such as } \\
\text { subject area. }\end{array}$ \\
\hline Motivation (A6) & $\begin{array}{l}\text { Although adult learners are } \\
\text { motivated by some external factors } \\
\text { such as promotions and salaries, } \\
\text { they are more driven by internal } \\
\text { factors such as enhanced quality of } \\
\text { life and desire for increased job } \\
\text { satisfaction. }\end{array}$ & $\begin{array}{l}\text { Traditional learners are more driven } \\
\text { by external factors such as } \\
\text { obtaining instructor recognition, } \\
\text { improved grades and parental } \\
\text { pressure. }\end{array}$ \\
\hline
\end{tabular}

Table 1 Comparison of the assumptions of the theory of adult and traditional learning

Albert, A and Hallowel, M R (2013) 'Revamping occupational safety and health training: Integrating andragogical principles for the adult learner', Australasian Journal of Construction Economics and Building, 13 (3) 128-140 


\begin{tabular}{|c|c|}
\hline Elements & Theory of adult learning (Andragogy) \\
\hline Preparing learners (E1) & $\begin{array}{l}\text { Andragogy model for adult learners assumes a high degree of learner } \\
\text { dedication and commitment to the self-directed learning process. Since } \\
\text { this form of learning is underutilized for educational purposes, and } \\
\text { trainees are conditioned to be dependent learners, preparatory sessions } \\
\text { are essential to develop self-directed learning proficiency. }\end{array}$ \\
\hline Climate (E2) & $\begin{array}{l}\text { A climate that is conducive to the learning process is essential. Both the } \\
\text { social (e.g. interpersonal relation) and the physical (e.g. layout, } \\
\text { acoustics) environment must be favorable allowing for comfort and the } \\
\text { free exchange of ideas. }\end{array}$ \\
\hline Planning (E3) & $\begin{array}{l}\text { Unlike the pedagogy counter-part, andragogy is based on the primary } \\
\text { theme of transforming learning processes from being teacher-directed to } \\
\text { self-directed. As such, the instructor plays the role of a facilitator who } \\
\text { collaborates with learners to develop and reinforce a learner-centered } \\
\text { learning experience. }\end{array}$ \\
\hline Diagnosis of needs (E4) & $\begin{array}{l}\text { Involving adult learners in the diagnosis of needs (mutual assessment } \\
\text { along with the facilitator) through the exposure to models portraying the } \\
\text { desired levels of performance, thereby facilitating comparisons between } \\
\text { current performance and the desired level of performance can motivate } \\
\text { and encourage learning. }\end{array}$ \\
\hline $\begin{array}{l}\text { Setting learning objectives } \\
\text { (E5) }\end{array}$ & $\begin{array}{l}\text { Based on the diagnosis of needs, the learner along with the facilitator } \\
\text { develop learning objectives through which learners can achieve the } \\
\text { newly established and desired level of performance. Such objectives } \\
\text { developed using mutual negotiations based on self-diagnosed needs } \\
\text { ensures commitment and active participation in the learning process. }\end{array}$ \\
\hline $\begin{array}{l}\text { Designing learning plans } \\
\text { (E6) }\end{array}$ & $\begin{array}{l}\text { After needs assessment and the setting of learning objectives, material } \\
\text { resources and active learning methods are carefully devised to facilitate } \\
\text { the mutual inquiry process. Several sequential and pro-active learning } \\
\text { methods that rely on the experience of learners are an essential } \\
\text { component of the adult learning process. }\end{array}$ \\
\hline Learning activities (E7) & $\begin{array}{l}\text { Learning activities must facilitate active participation of all learners in the } \\
\text { mutual inquiry process. A skilled facilitator with adequate knowledge on } \\
\text { adult learning process is essential to the angagogy-based adult learning } \\
\text { experience. Several hands-on and experimental activities can be } \\
\text { effectively used to improve learner interest. }\end{array}$ \\
\hline Evaluation (E8) & $\begin{array}{l}\text { To reinforce a continuous improvement culture, evaluations are essential } \\
\text { to verify if learning objectives were met and the degree to which desired } \\
\text { outcomes were achieves. Any weakness found can be incorporated in } \\
\text { the next iterative learning process. }\end{array}$ \\
\hline
\end{tabular}

Table 2 Andragogical process design elements

\section{Incorporating Andragogical Learning Principles into Construction Hazard Recognition Training Programs}

In order to accelerate the adult learning process and to improve the efficacy of construction safety training programs, andagogical principles should be integrated into existing workertraining protocols. Such proactive learning processes, unlike traditional reactive methods, are designed to improve knowledge retention, retrieval and application in practical settings. To

Albert, A and Hallowel, M R (2013) 'Revamping occupational safety and health training: Integrating andragogical principles for the adult learner', Australasian Journal of Construction Economics and Building, 13 (3) 128-140 
facilitate the integration process, a new andragogy-based construction safety training framework is proposed as shown in Figure 3.

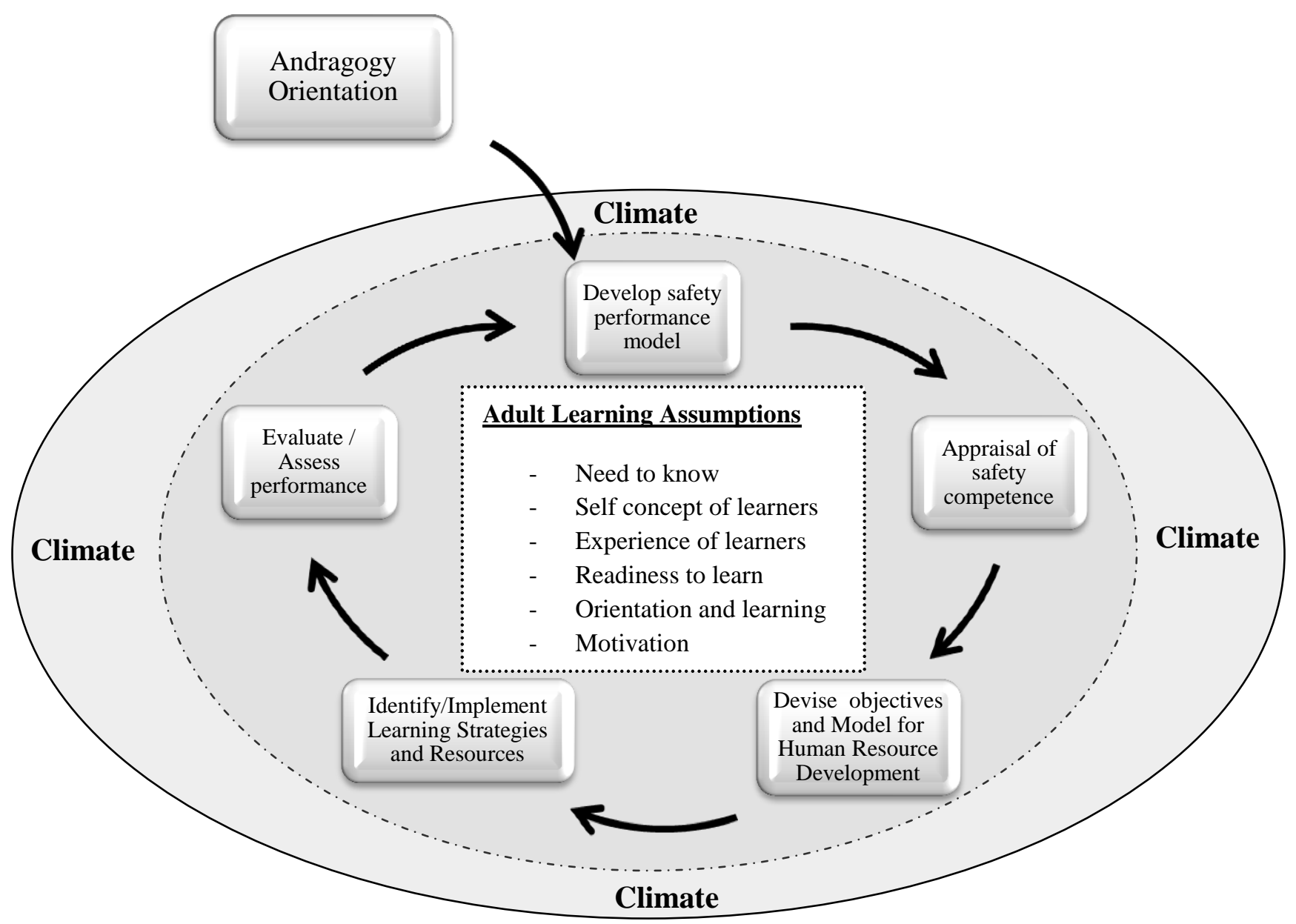

Figure 3 Andragogy based safety training framework

As can be seen in Figure 3, the integration framework is built based on the core established assumptions of how adults learn (see Table 1). To assist workers become familiar with this new technique of proactive learning, the cyclic process begins with an orientation program. This session introduces adult learners to the theory and practices of adult learning and the role played by individual self-directing adult learners. After learners have sufficiently grasped the essential concepts, the formal training process begins with a collaborative session where the learners and the facilitator work together to build a model for the safety management process in order to attain desired level of safety performance. This is followed by a session where the learners self-asses and compare their current safety management process and safety performance level to the desired model. This process reveals discrepancies between the current level of safety performance and the desired level. As a result, the learners understand the shortcoming with the currently established program, through which they perceive that improvement is required and attainable. This inductive process assists in the development of specific strategies and action items that can be implemented to attain desired level of performance. Also, various learning resources that are essential to attain set-goals can be collaboratively identified. Finally, the effectiveness of the collaborative learning process is evaluated, the safety performance is

Albert, A and Hallowel, M R (2013) 'Revamping occupational safety and health training: Integrating andragogical principles for the adult learner', Australasian Journal of Construction Economics and Building, 13 (3) 128-140 
measured and a revised safety process model is devised. An environment (climate) that is conducive for mutual learning and inquiry is essential for the successful implementation of the andragogy based training framework. The framework elements are discussed in more detail below.

\section{Andragogy Orientation}

Although adult learners feel the inherent need to be self-directing and responsible for their own learning, they are accustomed to passive pedagogy-based training approaches. As a result, workers will first need to be oriented to the andragogy-based safety training framework through preparatory sessions. Such preparatory sessions are specifically essential to orient new-hires and non-proficient workers who are unfamiliar with andragogy principles. In this orientation session, workers are prepared to distinguish pro-active approaches to learning from traditional reactive methods. Also, the diverse experience of the learners as a primary resource needs to be alluded to, and the importance of utilizing this resource need to be clearly communicated.

\section{Develop a Safety Performance Model}

After initial orientation, a model of desired safety performance is collaboratively developed. This developed model will eventually expose areas and skill-sets that the workers lack, which can then be developed through self-directed learning approaches. Although, the learners may be unable to provide adequate input during the first iterative use of the andragogy-based framework, the facilitator may provide examples and models from outside sources. For example, a competent facilitator with adequate knowledge on industry best-practices on conducting an ideal 'pre-job safety meeting', based on his past experience with other organizations can provide example models to assist learners develop their own customized model of performance. Such collaborative approaches assist workers in understanding the significance of acquiring additional knowledge and skill-sets that will be essential for their wellbeing. Further, customized models of desired performance that are self-developed will motivate workers to learn in order to attain set goals.

\section{Appraisal of Safety Competence}

After having developed the desired model of safety performance, construction employees can compare their current safety performance levels with the desired level of performance as developed in the previous phase. Such self assessment methods reveal areas where learning is required, and clearly communicates discrepancies that exist between current performance and the performance levels they desire to attain. Further, construction employees collaboratively discuss and recognize the benefits of improving performance. The facilitator ensures and provides the employees with proper procedures and tools to make valid comparisons and responsible judgments. Also, the facilitator ensures that all areas that require additional learning are well addressed. As per the previous example, workers can compare their current form of 'pre-job safety meeting' with the collaboratively developed model to identify areas that require improvement.

\section{Devise Objectives and Model for Human Resource Development}

After identifying discrepancies and areas that need improvement having, clear objectives and plans are devised to develop worker competency in currently underperforming areas. In traditional training methods, the instructor sets the learning objectives and plans, which is directly in conflict with andragogical assumptions that suggest that adults prefer self-directing learning methods. In the suggested andragocical framework, however, the adult learners collaboratively brainstorm and develop learning objectives and create action plans to attain desired performance levels. This method of developing learning objectives and action plans

Albert, A and Hallowel, M R (2013) 'Revamping occupational safety and health training: Integrating andragogical principles for the adult learner', Australasian Journal of Construction Economics and Building, 13 (3) 128-140 
based on self-diagnosed needs ensures worker commitment and eases any form of resistance to pursue self-set goals.

\section{Identify/Implement Learning Strategies and Resources}

For each self-identified learning need, specific strategies and learning resources must be identified and appropriately implemented in the pro-active learning process. The facilitator and the adult learners identify specific procedures or techniques that can effectively satiate the needs of the learners to improve. An ideal mix of individual and group activities along with experimental learning processes can be used. A wide array of resources including material resources, well-informed facilitators, simulations, media, relevant literature and others must be made available to the learners to accelerate adult learning processes.

\section{Measurement and Assessment}

In order to ensure continuous improvement and learning, measurement and assessment is necessary. According to Kirkpatrick (1998), the evaluation should be conducted in four levels (1) response from the adult learners to the andragogy process; (2) knowledge and skills acquired through the learning experience; (3) behaviour change induced as a result of the program; (4) benefits (e.g. lower injury rate, turnover) received through the improvement in performance. Such form of measurements also facilitates re-diagnosis of areas that may need improvement in the iterative adult training process.

\section{Climate}

An environment that is conducive to the adult learning process is necessary for successful implementation. The climate must provide a safe environment of mutual respect and trust that is accepting of differences in opinion and perspective and above all organizational commitment to safety improvement. Also, learners should have easy access to facilitators with a good understanding of andragogical principles and suitable learning resources. Finally, physical characteristics like ventilation, light, ambient temperature and others may notably affect interest in the learning process.

The andragogy-based safety training framework incorporates all the andragogy assumptions (see Table 1) and process elements (see Table 2) discussed in the paper. Table 3 presents each of the framework components (see Figure 3) along with its associated assumption and process element based on the codes provided in Table 1 and 2 (in parentheses). For example, considering the Appraisal of Safety Competence component, the adult learner makes a comparison of the current safety management process or performance with the desired model based on previous experience (Experience of learners - A3). Through this process, the adult learner discerns areas of discrepancies or underperformance such as high injury rates (Need to know - A1) by themselves (Self-concept of learners - A2). This self-recognized weakness motivates (Motivation - A6) adult learners to seek practical solutions (Readiness to learn - A4), thus orienting (Orientation to learning - A5) them to pursue the desired level of safety performance. Hence the Appraisal of Safety Competence component takes into consideration all the androgogy assumptions presented in Table 1.

This benchmarking process of comparing current performance with desired level of performance involves the adult learner in the diagnosis of needs (Diagnosis of needs - E4) as they recognize areas that need improvement. Also, such a collaborative process requires a favorable climate (Climate - E2) that promotes mutual inquiry. Thus, the Appraisal of Safety Competence component also incorporates two andragogy process design elements from Table 2.

Albert, A and Hallowel, M R (2013) 'Revamping occupational safety and health training: Integrating andragogical principles for the adult learner', Australasian Journal of Construction Economics and Building, 13 (3) 128-140 


\begin{tabular}{|l|l|l|}
\hline Framework components & Assumptions & Elements \\
\hline Andragogy Orientation & A5 A6 & E1 E2 \\
\hline Develop Safety Performance Model & A1 A2 A3 A5 A6 & E2 E3 \\
\hline Appraisal of safety competence & A1 A2 A3 A4 A5 A6 & E2E4 \\
\hline Devise objectives and Model for Human Resource Development & A2 & E2 E3 E5 \\
\hline Identify/lmplement Learning Strategies and Resources & A2 A3 & E2 E6 E7 \\
\hline Evaluate / Assess Performance & A6 & E8 \\
\hline
\end{tabular}

Table 3 Incorporation of andragogy assumptions and process elements

\section{Case Example}

In a preliminary attempt to test the feasibility of applying the androgogy- based training framework to improve hazard recognition, the authors selected three crews (civil, maintenance, and mechanical) from an industrial construction project located in the southern United States. In total, 16 workers went through the training module.

\section{Step 1: Andragogy Orientation and Development of Climate that is conducive for mutual inquiry}

The process began with an orientation to andogogy principles. In this session, the facilitator simply communicated the new pro-active roles of the workers, and used an engaging exercise to encourage active participation from the workers. Specifically, the facilitator presented workers with a series of construction photographs, and asked workers to identify hazards and poor work practices. Using their knowledge from past experience, the workers pro-actively identified hazards, discussed alternative and safer methods to complete the same tasks, and suggested injury prevention methods for each scenario. Following this, the facilitator initiated discussions about the importance of hazard recognition, in which the workers actively participated.

\section{Step 2: Develop a Safety Performance Model}

After the orientation, the facilitator initiated discussions about methods that are generally used to identify hazards on typical construction projects, and limitations associated with these methods. The workers identified several common methods, such as the use of work-site check-lists, job safety analysis (JSA) and other. The limitations associated with these methods were recorded on a white board. Examples of limitations included the inability of check-lists to account for all hazards in a dynamic environment and the insensitivity of the JSA process to hazards that workers may be exposed to while working adjacent to other crews. As such, a model protocol was developed and discussed to address limitations associated with traditional hazard recognition methods and to improve the proportion of hazards identified. Since, workers were unfamiliar with developing such protocols, the facilitator provided useful input, and shared a model that was used by another organization. This model provided important guidelines and procedures to conduct a pre-job hazard analysis meeting. Specifically, the model provided (1) techniques to identify hazards associated with job tasks, (2) ideal location for conducting the meeting, (3) defined roles of supervisors and the crew members, (4) an efficient method to document and communicate hazards, and (5) methods to identify additional hazards when job changes occur. Based on collaborative discussions, the model was customized for the workers needs.

Albert, A and Hallowel, M R (2013) 'Revamping occupational safety and health training: Integrating andragogical principles for the adult learner', Australasian Journal of Construction Economics and Building, 13 (3) 128-140 


\section{Step 3: Appraisal of Safety Competence and Devising Learning Objectives}

Following the development of the desired model, the workers self-assessed current methods that they utilized with the new model. Areas where improvement was needed were discussed elaborately. Also, the facilitator, once again presented a sub-sample of photographs which were used in Step 1 and revealed important hazards that the workers did not identify in the initial exercise. Adequate time was allocated to discuss the unidentified hazards, and the consequences of not identifying significant conditions or behaviors that can cause harm. As indicated previously, the appraisal session allowed workers to self-assess their ability to recognize hazards allowing the development of precise learning objectives. In this case, the learning objectives were to identify techniques, procedures and resources that can assist improving hazard recognition skills

\section{Step 4: Identify/lmplement Learning Strategies and Resources}

In the final stage, workers discussed specific techniques to incorporate guidelines from the devised model in Step 2. The facilitator also assisted in developing methods to improve hazard recognition. For example, the facilitator presented eight energy categories that were proposed by Fleming (2009) to assist in hazard recognition. According to this method, the inappropriate release of specific energy sources (e.g. electricity, radiation) in the construction environment creates the potential for injury occurrence. Workers could review each energy source to identify hazards relevant to their job-task.

\section{Step 5: Measurement and Assessment}

Although practical constraints did not allow measurement and assessment in the four levels as proposed by Kirkpatrick, the site-safety professional communicated to the researchers that traditional learning programs typically used were less interactive. Also the facilitator presented a different sub-sample of the photographs used in Step 1, but not in Step 3. Several additional hazards were identified that were not identified in Step 1. As such, there is some indication that workers were able to recognize a higher proportion of hazards. Also, workers feedback suggested that they were able to identifying more hazards after the interactive exercise.

\section{Future Research Recommendations}

The ultimate aim of developing effective hazard recognition training programs is to equip workers with skill-sets that are necessary to recognize and respond to hazards on dynamic construction environments. Although very promising, the integration of andragogical principles to improve construction safety training programs is relatively new and has not been investigated adequately. As such, future research will focus on validating the developed andragogy based training framework using focus group sessions with construction safety trainers and several experts in the field on andragogy research.

Following validation, a psychometric measurement tool will be developed using the assumptions and the process elements of andragogy to study the effects of the collaborative learning approach on safety performance and the development of hazard recognition skills. Several studies will be undertaken to test the null hypothesis that the devised andragogy-based safety training framework will not significantly improve safety performance or hazard recognition skills of construction employee. In these follow-up studies, if a relationship exists, then predictive models of safety performance while using the andragogy based-framework will be developed and disseminated to construction trainers. Also, since employee interaction and mutual inquiry are essential components of the andragogy based training process, model sociograms may be developed to measure the effectiveness of the collaborative pro-active approach to learning.

Albert, A and Hallowel, M R (2013) 'Revamping occupational safety and health training: Integrating andragogical principles for the adult learner', Australasian Journal of Construction Economics and Building, 13 (3) 128-140 


\section{Conclusion}

Prior research has established that construction employees are unable to recognize and respond appropriately to construction hazards. Several researchers have attributed this lack in skill-sets to insufficient and ineffective training programs within the construction sector. The aim of this paper was to propose a reliable 'andragogy based safety training framework' incorporating the adult cognitive learning process to improve hazard recognition and safety performance in the construction sector. This was accomplished by reviewing relevant literature to understand how adults learn and through the incorporation of unique methods to improve adult knowledge retention and retrieval. This framework can be adopted by construction safety trainers and educators to integrate andragocial principles into existing training programs. It is expected that the framework will stimulate construction employees to pro-actively partake in developing safety objectives and training programs to improve hazard recognition levels and construction safety.

\section{Reference}

Ahmed, S., Kwan, J., Ming, F. \& Ho, D. 2000, 'Site-Safety Management in Hong Kong', Journal of Management in Engineering, 16 (6), 34-42.

Cameron, I., Hare, B. \& Davies, R. 2008, 'Fatal and major construction accidents: a comparison between Scotland and the rest of Great Britain', Safety Science, 46 (4) 692-708.

Carter, G. \& Smith, S.D. 2006, 'Safety hazard identification on construction projects', Journal of Construction Engineering and Management, 132 (2), 197-205.

Findley, M., Smith, S., Kress, T., Petty, G. \& Enoch, K. 2004, 'Safety program elements in construction', Professional safety, 49 (2), 14-21.

Fleming, M. A. 2009, 'Hazard recognition.' By Design, ASSE, 11-15

Forrest, S.P. \& Peterson, T. 2006, 'It's Called Andragogy', Academy of Management Learning \& Education, 5 (1), 113-122.

Haslam, R., Hide, S., Gibb, A.G., Gyi, D.E., Pavitt, T., Atkinson, S. \& Duff, A. 2005, 'Contributing factors in construction accidents', Applied Ergonomics, 36 (4), 401-415.

Health and Safety Executive, 2012, Enforcement policy statement, available at http://www.hse.gov.uk/pubns/hse41.pdf

Hinze, J., Thurman, S. \& Wehle, A. 2013, 'Leading indicators of construction safety performance', Safety Science, 51 (1), 23-28.

Holte, K.A. \& Kjestveit, K. 2012, 'Young workers in the construction industry and initial OSHtraining when entering work life', Work: A Journal of Prevention, Assessment and Rehabilitation, 41, 4137-4141.

Holton, E.F., Swanson, R.A. \& Naquin, S.S. 2001, 'Andragogy in practice: Clarifying the andragogical model of adult learning', Performance Improvement Quarterly, 14 (1), 118-143.

Huang, X. \& Hinze, J. 2006, 'Owner's role in construction safety', Journal of Construction Engineering and Management, 132 (2), 164-173.

Kirkpatrick, D.L. 1998, Evaluating training programs: the four levels, Berrett-Koehler Publishers, San Francisco, Calif.

Knowles, M.S., Holton, E.F. \& Swanson, R.A. 2011, The adult learner: the definitive classic in adult education and human resource development, Elsevier Butterworth-Heinemann, Amsterdam [etc.].

Albert, A and Hallowel, M R (2013) 'Revamping occupational safety and health training: Integrating andragogical principles for the adult learner', Australasian Journal of Construction Economics and Building, 13 (3) 128-140 
Larson, J. 2006, 'Intersection of Andragogy and Distance Education: Handing over the Reins of Learning to Better Prepare Students for the Practice of Law, The', TM Cooley J.Prac.\& Clinical L., 9, 117.

Lindeman, E.C., Gessner, R. \& Otto, M. 1956, The democratic man: Selected writings of Eduard C. Lindeman, Boston.

Misch, D.A. 2002, 'Andragogy and medical education: Are medical students internally motivated to learn?', Advances in Health Sciences Education, 7 (2), 53-160.

Mitropoulos, P., Abdelhamid, T.S. \& Howell, G.A. 2005, 'Systems model of construction accident causation', Journal of Construction Engineering and Management, 131 (7), 816-825.

Pinto, A., Nunes, I.L. \& Ribeiro, R.A. 2011, 'Occupational risk assessment in construction industry-Overview and reflection', Safety Science, 49 (5), 616-624.

Rogers, C.R. 1995, On becoming a person: a therapist's view of psychotherapy, Houghton Mifflin Company, Boston; New York.

Roudsari, B.S. \& Ghodsi, M. 2005, 'Occupational injuries in Tehran', Injury, 36 (1), 33-39.

Safe Work Australia, (2009). Work-related injuries in Australia, 2005-06, available at http://www.safeworkaustralia.gov.au/sites/SWA

Safe Work Australia, (2009). Explantory memorandum - Model work health and safety bill, available at http://www.safeworkaustralia.gov.au/sites/swa/model-whs-laws/model-whsact/pages/model-whs-act

Taylor, B. \& Kroth, M. 2009, 'Andragogy's Transition into the Future: Meta-Analysis of Andragogy and Its Search for a Measurable Instrument', Journal of Adult Education, 38 (1), 111.

Waehrer, G.M., Dong, X.S., Miller, T., Haile, E. \& Men, Y. 2007, 'Cost of occupational injuries in construction in the United States', Accident Analysis \& Prevention, 39 (6), 258-1266.

Wang, Y., Goodrum, P.M., Haas, C., Glover, R. \& Vazari, S. 2010, 'Analysis of the benefits and costs of construction craft training in the United States based on expert perceptions and industry data', Construction Management and Economics, 28 (12), 1269-1285.

Wilkins, J.R. 2011, 'Construction workers' perceptions of health and safety training programmes', Construction Management and Economics, 29 (10), 1017-1026.

Albert, A and Hallowel, M R (2013) 'Revamping occupational safety and health training: Integrating andragogical principles for the adult learner', Australasian Journal of Construction Economics and Building, 13 (3) 128-140 